\title{
Swimming capacity and pleopod beat rate as a function of sex, size and moult stage in Northern krill Meganyctiphanes norvegica
}

\author{
M. A. Thomasson ${ }^{1, *}$, M. L. Johnson ${ }^{2}$, J.-O. Strömberg ${ }^{1}$, E. Gaten ${ }^{3}$ \\ ${ }^{1}$ Kristineberg Marine Research Station, 45034 Fiskebäckskil, Sweden \\ ${ }^{2}$ Scarborough Centre for Coastal Studies, University of Hull, Filey Rd., Scarborough YO11 3AZ, United Kingdom \\ ${ }^{3}$ Biology Department, University of Leicester, University Rd., Leicester LE1 7RH, United Kingdom
}

\begin{abstract}
An experimental method to estimate the relative swimming capacity of pelagic crustaceans is proposed. Swimming capacity measured as propulsive force can be estimated by attaching the animal to a virtually friction free rotational displacement transducer with an arm allowing only forward and backward movements. The method also allows determination of beat rates of the pleopod cycle. Results from the use of the method on different sizes, sexes and moult stages of Northern krill Meganyctiphanes norvegica indicate that the swimming capacity of krill increases with the size of the animal, although pleopod beat frequency decreases with increasing size of the animal. We found no difference in swimming capacity between females and males, but female krill had a higher pleopod beat frequency than males. The moult stage of the animal affects the swimming capacity, with newly moulted krill being weaker swimmers. It also affects pleopod beat frequency, with newly moulted krill having the lowest frequency. We argue that results of this kind may be useful in attempts to interpret observed demographic distribution patterns in migration studies as well as in studies of krill population dynamics.
\end{abstract}

KEY WORDS: Krill $\cdot$ Swimming capacity $\cdot$ DVM $\cdot$ Moult stage $\cdot$ Pelagic ecophysiology

Resale or republication not permitted without written consent of the publisher

\section{INTRODUCTION}

The Northern krill Meganyctiphanes norvegica occupies a central position in North Atlantic and western Mediterranean pelagic food-webs (e.g. Mauchline \& Fisher 1969, Mauchline 1980). The species is found both in fjord environments and in open water areas and may be of key importance regionally both as a consumer of plankton and as prey for both exploited and non-exploited fish species (e.g. Mauchline 1980, Dalpadado et al. 2000).

As with many other euphausiids, Meganyctiphanes norvegica has been shown to have a daily vertical migration rhythm (Mauchline 1980) such that they move closer to the surface during the night and migrate to greater depths during the day. Most of what is known about the behavioural ecology and vertical migration of pelagic species, such as the euphausiid $M$. norvegica, is derived from investigations using nets (e.g. Roe et al. 1984, Buchholz \& Boysen-Ennen 1988, Tarling et al. 1999) or through acoustic methods (e.g. Onsrud \& Kaartvedt 1998, Tarling et al. 1999, Liljebladh \& Thomasson 2001).

Meganyctiphanes norvegica is a highly motile species that, since it is negatively buoyant, has to swim constantly to avoid sinking (Kils 1981). Krill use their pleopods for forward motion but can also perform rapid backward 'tail-flips' as an escape response (Kils 1981). The vertical movement of $M$. norvegica swarms has been estimated with the aid of acoustic doppler current profilers as 1 to $3 \mathrm{~cm} \mathrm{~s}^{-1}$ (Buchholz et al. 1995, Liljebladh \& Thomasson 2001), which agrees with laboratory measurements of the swimming speed of individual krill, around $3 \mathrm{~cm} \mathrm{~s}^{-1}$ (Hardy \& Bainbridge 
1954). However, Kils (1981) estimated the maximum swimming speed of Antarctic krill Euphausia superba to be as fast as 8 times its body length per second for pleopod swimming in situ.

Krill locomotory capacity may be influenced by a variety of factors. The moult cycle has been shown to influence krill behaviour. Tarling et al. (1999) suggested that the vast majority of freshly moulted krill probably remain at depth throughout the diurnal cycle. This and other factors affect migration and probably distribution patterns in a secondary manner, through exposure to variable advective patterns (Bergström \& Strömberg 1997). For crustaceans in general, the moult cycle is divided into several stages, from Stage A, newly moulted, to Stage E, ecdysis (Passano 1960). Buchholz (1982, 1991) and Cuzin-Roudy (1987) have described the moult cycle for euphausiids which includes 7 stages, A, B, C, D0, D1, D2 and D3, but also several substages. Apolysis takes place towards the end of Stage C which is followed by Stage D0 when the epidermis is completely detached from the cuticle (Cuzin-Roudy \& Buchholz 1999). Before and after ecdysis, from Stage D3 until Stage A, the cuticle is soft (Buchholz 1991, Cuzin-Roudy \& Buchholz 1999). Once the animal has reached $\mathrm{E}$ it moults within seconds.

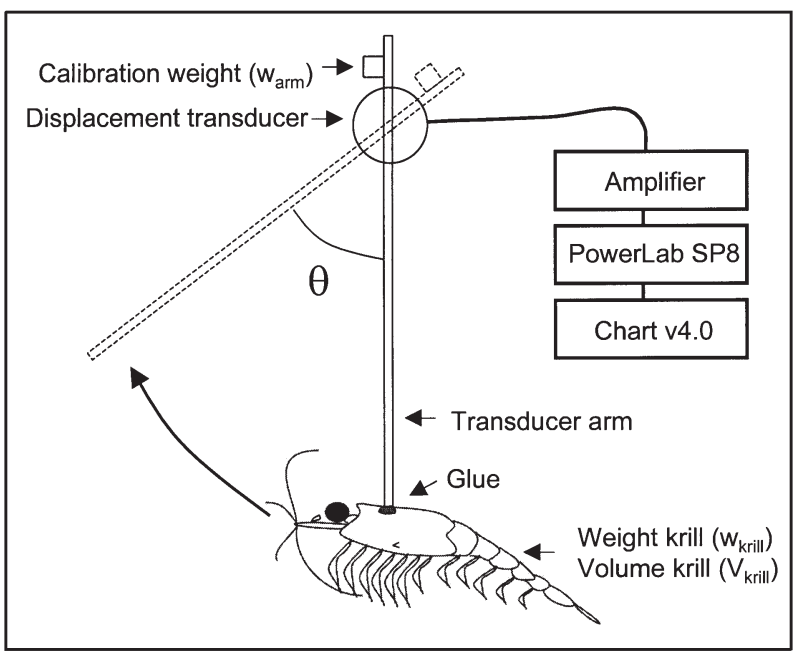

Fig. 1. Meganyctiphanes norvegica. Experimental set-up, showing the principles of the pendulum technique. The animal was glued to the transducer arm. Movement of the arm, caused by the animal swimming, was measured in $\mathrm{mV}$ and recorded on a Power Lab SP8, software Chart v.4.0. The mV readings were translated into angle displacement $(\theta)$, which was used for calculating swimming capacity $\left(F_{\mathrm{p}}\right)$, i.e. propulsive force in Newtons, for each animal. The following formula was used: $F_{\mathrm{p}}=\left(w_{\text {krill }}-\left(\rho_{\mathrm{H}_{2} \mathrm{O}} \times V_{\text {krill }}\right)+w_{\text {arm }}\right) \times g \times \operatorname{Sin} \theta$, where $W_{\text {krill }}=$ wet weight of krill in $\mathrm{kg}, \rho_{\mathrm{H}_{2} \mathrm{O}}=$ specific density of sea water in $\mathrm{kg} \mathrm{l}^{-1}, V_{\text {krill }}=$ volume of the krill in $1, w_{\text {arm }}=$ calibration weight of the transducer arm in $\mathrm{kg}$ and $g=$ acceleration due to gravity in $\mathrm{m} \mathrm{s}^{-2}$ (taken as 9.82)
In crustaceans, the moult cycle is closely related to the growth and reproductive cycles, and consequently many studies link both factors (e.g. Buchholz 1991, Gonzalez-Gurriaran et al. 1995, Cuzin-Roudy \& Buchholz 1999). Few have investigated how the locomotory capacity might change throughout the moult cycle, and those studies have mainly been restricted to decapods (e.g. Lipcius \& Herrnkind 1982, Cromarty et al. 1991).

Although attempts have been made to examine the behaviour of pelagic crustaceans in aquaria, either freely swimming (e.g. Land 1992, Torgersen 2001) or tethered (e.g. Frank \& Widder 1994), analyses of observations from such experiments are necessarily subjective and the conclusions reached must be treated with some caution.

Against this background, the aim of this paper is to describe a simple laboratory method which allows comparisons of individual pelagic crustacean swimming capacity. We applied this method to different sizes of both male and female Meganyctiphanes norvegica and to different stages in their moult cycle, and assessed how these factors might affect swimming capacity and performance.

\section{MATERIALS AND METHODS}

Krill sampling and maintenance. Experiments were performed during 2 periods in 2001, at the end of May and in mid-September. Krill Meganyctiphanes norvegica were caught during the day in the deep basin of the Gullmarsfjord (90 to $100 \mathrm{~m}$ ), west coast of Sweden $\left(58^{\circ} 19.00^{\prime} \mathrm{N}, 11^{\circ} 33.00^{\prime} \mathrm{E}\right)$, using an Isaacs-Kidd midwater trawl (mouth size $0.6 \mathrm{~m}^{2}$, mesh size $1500 \mu \mathrm{m}$ ). Haul duration was $10 \mathrm{~min}$ and the towing speed 3 knots.

In the laboratory, krill were kept in the dark in a 3501 covered opaque fibre-glass tank supplied with constantly running, temperature controlled seawater taken from the fjord $\left(10^{\circ} \mathrm{C}, 33.5 \mathrm{PSU}, \mathrm{O}_{2}>80 \%\right)$. Animals were not fed, but the seawater supplied to the storage tank came from $35 \mathrm{~m}$ depth in the fjord through a pipeline and contained particles and organisms found in the water at that depth. The animals were used experimentally within $5 \mathrm{~d}$ of capture.

Experimental set-up. Krill swimming capacity was measured by attaching the animal to a TRO 015 (Panlab, Barcelona) virtually friction-free rotational displacement transducer (Fig. 1), so that only forward and backward movements were possible. Animals were attached to the transducer arm along the dorsal mid-line of the carapace using cyanoacrylate glue. We assumed that gluing did not affect the swimming ability of the krill since it did not affect any exoskeleton parts in- 
volved in locomotion. Transfer of free-swimming krill from the storage aquarium to the experimental chamber (including gluing to the transducer arm) took less than $20 \mathrm{~s}$. The experimental chamber consisted of a $43 \times 26 \times 23 \mathrm{~cm}$ tank placed within another tank which had through-flow of cooling water. This arrangement allowed us to maintain the water temperature at $10^{\circ} \mathrm{C}$ without disturbing the displacement transducer or the swimming activity of the animal with flowing water. Water salinity in the experimental chamber was 33.5 PSU and the oxygen saturation was $>80 \%$. Four identical set-ups were used during the experiment so that recordings from 4 krill specimens, in 4 different experimental chambers, were carried out simultaneously. Disturbance to the animals was minimized by housing the experimental tank in the dark. We accept that capturing, confining and handling the krill for the experiments introduce stress to these pelagic animals, but since handling was consistently brief we assume that the associated stress was equal in all individuals. Hence we believe that our measurements are valid for inter-individual comparisons.

Movement of the transducer arm caused by swimming activity of the krill produced a signal recorded on a PowerLab SP8 (AD Instruments), software Chart v4.0, set at a sampling rate of $40 \mathrm{~Hz}$. Since the transducer had a linear response, the movement of the arm, measured in $\mathrm{mV}$, could be translated to angle displaced by measuring $\mathrm{mV}$ at maximum and minimum angle for each individual transducer. The transducer arm was equipped with a pre-calibrated counterweight which could be set from 0 to $5 \mathrm{~g}$, and this weight had to be lifted by the swimming animal. Depending on the size (i.e. strength) of the animal, this weight was set between 0.25 and $2.25 \mathrm{~g}$ in the experiment to keep the angle $(\theta)$ in the correct range, i.e. to calibrate the weight of the arm. The traces generated allowed estimation of displacement, pleopod beat frequency, swimming bout frequency and activity duration for each animal. Swimming capacity $\left(F_{\mathrm{p}}\right)$, i.e. propulsive force in Newtons, was calculated from:

$$
F_{\mathrm{p}}=\left[w_{\text {krill }}-\left(\rho_{\mathrm{H}_{2} \mathrm{O}} \times V_{\text {krill }}\right)+w_{\text {arm }}\right] \times g \times \operatorname{Sin} \theta
$$

where $w_{\text {krill }}=$ wet weight of krill in $\mathrm{kg}$ (total mass), $\rho_{\mathrm{H}_{2} \mathrm{O}}=$ specific density of sea water in $\mathrm{kg} \mathrm{l}^{-1}$ (taken as $1.03), V_{\text {krill }}=$ volume of the krill in $l, w_{\text {arm }}=$ calibration weight of the transducer arm in $\mathrm{kg}, g=$ acceleration due to gravity in $\mathrm{m} \mathrm{s}^{-2}$ (taken as 9.82) and $\theta=$ angle through which the arm was displaced. Animals were left undisturbed for $10 \mathrm{~min}$ before recording $30 \mathrm{~min}$ of swimming activity, and were then removed for analysis. The animals were then weighed, their volumetric displacement measured and total length from the front of the eye to the end of the telson was measured using electronic calipers. The recorded data were analysed in software Chart v4.0 with the first 5 min excluded to allow tests and checks of the recording system. Consequently, maximum and mean power outputs were taken from 25 min of swimming activity for each animal. The cycle frequency of the pleopods could be measured since the regular motion of the pleopods caused the transducer arm to vibrate slightly as the animal swam. In many animals this was difficult to pick out against the larger movements generated as a result of swimming bouts. Using the Spectrum function in Chart v4.0, it was however possible to calculate pleopod beat frequency through discrete fast Fourier transformation (FFT). The sampling rate must be at least twice the rate of the highest expected frequency to get an accurate digital signal recorded from an analogue signal (the Nyquist frequency). Thus, a sampling rate of $40 \mathrm{~Hz}$ was well above the minimum required since the expected cycle frequency of the pleopods was around $6 \mathrm{~Hz}$ (Wiese \& Ebina 1995). The number of FFTs was around 450 and the number of data points in each FFT was 256.

Moult staging and size distribution. Moult stage was determined immediately after the animal was removed from the pendulum using live preparation of the antennal scale examined under a light microscope. Moult staging was carried out according to the classifications of Buchholz $(1982,1991)$ and Cuzin-Roudy \& Buchholz (1999). The following 15 stages were identified: A/B, B, B/C early, C, Clate, D0, D0 late, D1 early, D1, $\mathrm{D} 1_{\text {late, }} \mathrm{D} 2, \mathrm{D} 2_{\text {late, }} \mathrm{D} 3_{\text {early, }} \mathrm{D} 3$ and D3 $3_{\text {late }} / \mathrm{E}$.

Since crustaceans generally lack internal solid structures that indicate seasonal growth like e.g. otholiths in fish, age determination in krill and shrimp is based on the analysis of sample length frequencies (e.g. Bergström 2000, Siegel \& Nicol 2000), where modes (cohorts) in the length frequency distribution are identified. Since the spawning season in Meganyctiphanes norvegica has a limited duration every year (Einarsson 1945), one can assume that cohorts represent year classes. Separation of the krill length-frequency data into cohorts was done in FiSAT (FAO-ICLARM Stock Assessment Tools), using Bhattacharya's method.

Statistical analyses. Statistical tests were performed using SuperANOVA v1.11 (Abacus Concepts). Differences in swimming capacity and differences in pleopod beat frequency in relation to sex and moult stage were analysed using a 1-way ANOVA. Possible interactions between cohorts and season in relation to swimming capacity were analysed using a 2-way ANOVA. The relationships between swimming capacity and size, and pleopod beat frequency and size, were analysed using simple linear regression. Multiple comparisons of means were carried out with a StudentNewman-Keuls test. Differences were considered significant when $\mathrm{p}<0.05$. 
Table 1. Meganyctiphanes norvegica. Percentage of the different moult stages observed in the krill populations used in the experiments in May $(n=98)$ and September $(n=134)$. Values are rounded to the nearest integer

\begin{tabular}{|lrc|}
\hline Moult stage & May & September \\
\hline A/B-B & 2 & 4 \\
B & 1 & 2 \\
B/C early $_{\text {C }}$ & 5 & 19 \\
C $_{\text {late }}$ & 19 & 28 \\
D0 & 11 & 6 \\
D0 $0_{\text {late }}$ & 7 & 4 \\
D1 early & 5 & 1 \\
D1 & 4 & 7 \\
D1 $1_{\text {late }}$ & 3 & 1 \\
D2 & 9 & 3 \\
D2 $2_{\text {late }}$ & 13 & 6 \\
D3 early & 1 & 1 \\
D3 & 13 & 8 \\
D3 $3_{\text {late }} / E$ & 3 & 4 \\
\hline
\end{tabular}

\section{RESULTS}

\section{Moult stages, age and size}

The percentage composition of the different moult stages is presented in Table 1. The most common stages in May were Stages C (19\%), D2 (13\%) and D3 $3_{\text {early }}(13 \%)$ and in September Stages C (28\%) and $\mathrm{B} / \mathrm{C}_{\text {early }}(19 \%)$. During May, around $60 \%$ of the animals sampled were approaching ecdysis (Stage D0 onwards) while in September the majority of animals were in a postmoult stage (Stages A to C).

The length-frequency distributions of the krill used in the experiments are shown in Fig. 2. Two cohorts were distinguished in both May and September, Agegroup 1, which consisted of animals hatched in 2000 and Age-group 2 with individuals hatched in 1999 or earlier. In the May experiments, the mean length for Group 1 was $30.7 \mathrm{~mm}$ and during September $34.7 \mathrm{~mm}$, and for Group 2 these values were 39.8 and $40.6 \mathrm{~mm}$, respectively. In May ( $\mathrm{n}=98$ ), $83 \%$ of the krill were males, while they comprised $61 \%$ of the population in September $(\mathrm{n}=134)$.

\section{Swimming capacity vs size}

Maximum and average swimming capacities in relation to size are shown in Fig. 3. According to linear regression analyses, there was a significant positive relationship for both maximum (ANOVA, $F_{1,227}=$ $27.107, \mathrm{p}<0.05$ ) and average (ANOVA, $F_{1,227}=19.178$, $\mathrm{p}<0.05)$ swimming capacity with total length of the animals. Note here that animals from the whole popu-
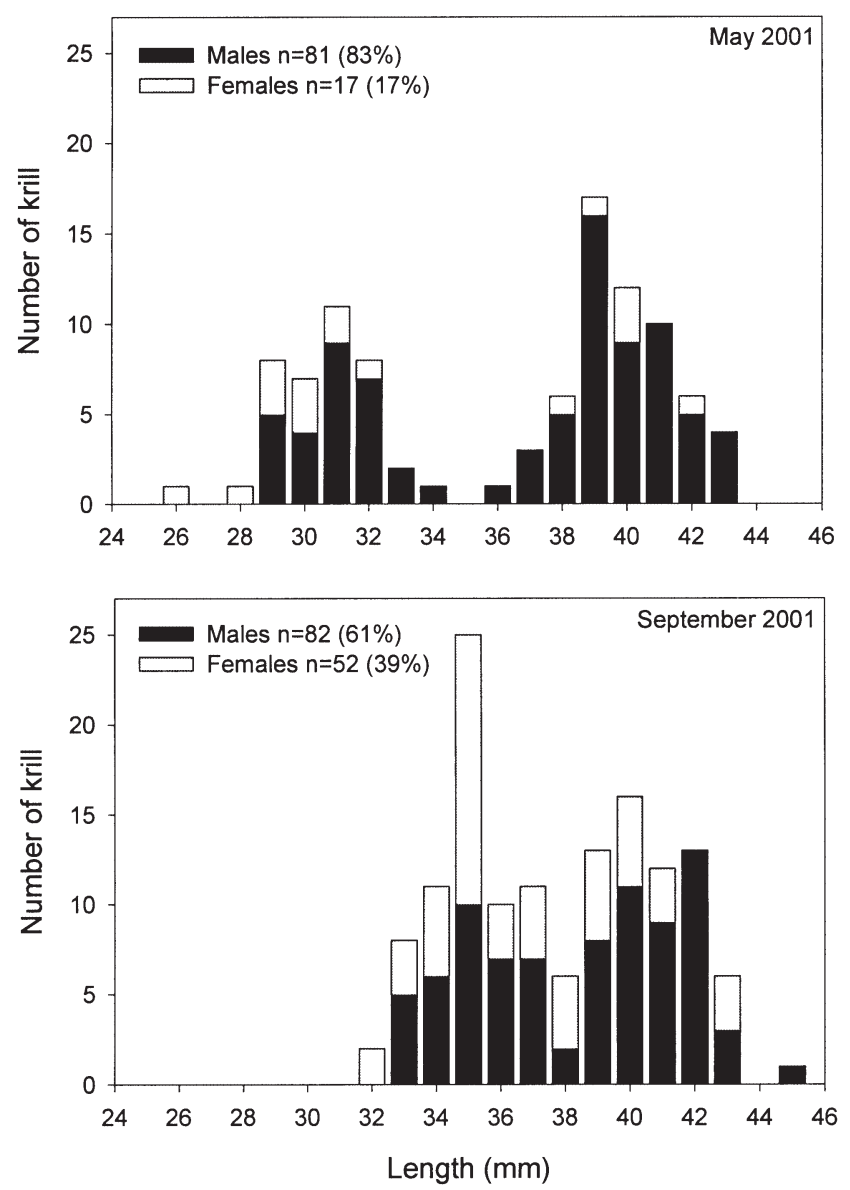

Fig. 2. Meganyctiphanes norvegica. Length-frequency distribution of the animals used in the experiments in May and September. The proportion of females and is also shown

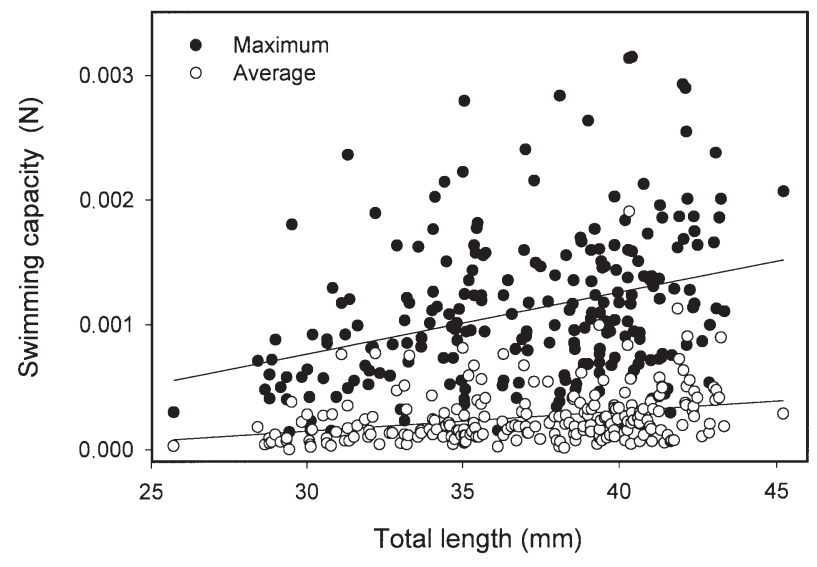

Fig. 3. Meganyctiphanes norvegica. Maximum and average swimming capacities (as propulsive force) by individual krill in relation to their total length. For the 'Maximum' curve, $y=$ $4.90 \times 10^{-5} \mathrm{X}-7.08 \times 10^{-4}, \mathrm{r}^{2}=0.11$, and for the 'Average' curve, $y=1.57 \times 10^{-5} x-3.25 \times 10^{-4}, r^{2}=0.08, n=229$ 


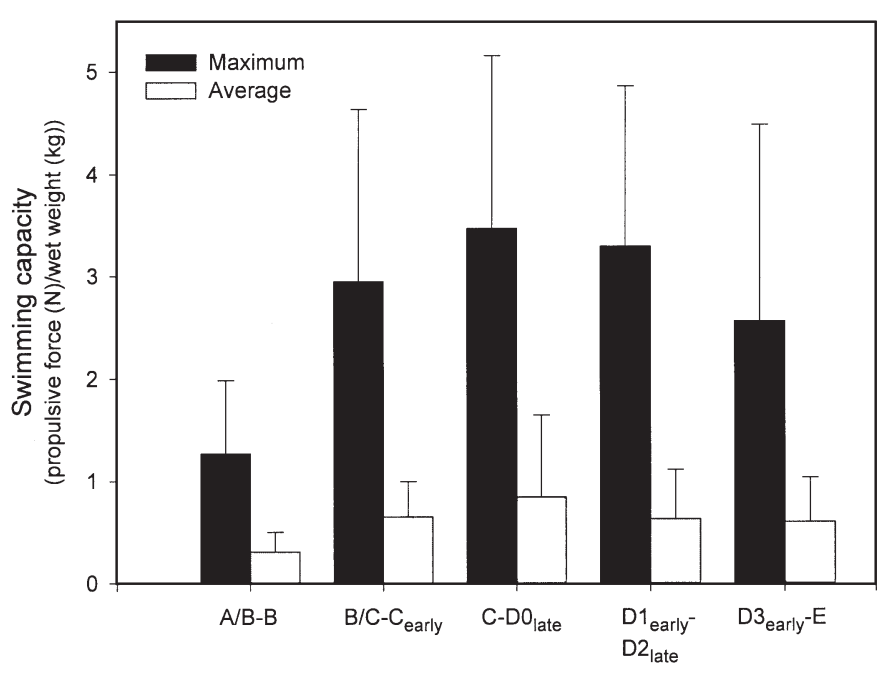

Fig. 4. Meganyctiphanes norvegica. Maximum and average (+SD) relative swimming capacities of krill, normalised to size, in relation to moult stage. $\mathrm{n}=11$ (Stage A/B-B), $\mathrm{n}=31$ (Stage $\left.\mathrm{B} / \mathrm{C}-\mathrm{C}_{\text {early }}\right), \mathrm{n}=95\left(\right.$ Stage $\left.\mathrm{C}-\mathrm{D} 0_{\text {late }}\right), \mathrm{n}=56$ (Stage D $\left.1_{\text {early }}-\mathrm{D} 2_{\text {late }}\right)$ and $\mathrm{n}=39$ (Stage D3 early $_{\text {-E) }}$

lation have been used and the different moult stages have not been taken into account.

\section{Swimming capacity vs sex}

There was no significant difference in either maximum or mean swimming capacity between males and females (ANOVA, $\left.F_{1,226}=0.226, \mathrm{p}>0.05\right)$.

\section{Swimming capacity vs moult stage}

The influence of moult stage on the swimming capacity in krill is shown in Fig. 4. The swimming capacity is likely to be a function of muscle volume and hence was normalised to size by division by total mass (wet weight). The different moult stages were

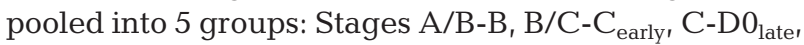
$\mathrm{D} 1_{\text {early }}-\mathrm{D} 2_{\text {late }}$ and $\mathrm{D} 3_{\text {early }}-\mathrm{E}$. There was a significant difference in swimming capacity between moult stages



Fig. 5. Meganyctiphanes norvegica. Interaction between cohort (Age-group 1 born in 2000, Age-group 2 born in 1999 or earlier) and season in relation to maximum and average $( \pm \mathrm{SD})$ swimming capacities normalised to size. There is a significant interaction between cohort and season (2-way ANOVA, $\mathrm{p}<0.05$ )

both at maximum (ANOVA, $F_{4,225}=5.866, \mathrm{p}<0.05$ ) and average (ANOVA, $F_{4,225}=3.292, \mathrm{p}<0.05$ ) lift. According to a Student-Newman-Keuls test, Stage A/B-B was significantly different from all other stages at maximum lift and from $\mathrm{C}-\mathrm{D} 0_{\text {late }}$ at average lift.

\section{Interaction between cohort and season in relation to swimming capacity}

The krill used in the experiments consisted of 2 cohorts in both seasons (May and September). A 2-way ANOVA showed a significant interaction between cohort and season (Table 2). The swimming capacity was normalised to size by division by total mass (wet weight). In May, the older (larger) krill had relatively less swimming capacity than the smaller ones, while in September, the swimming capacity seemed to have increased for Agegroup 2 and decreased for Age-group 1, resulting in a similar capacity for both groups (Fig. 5).

\section{Pleopod beat frequency vs size}

Fig. 6 shows an example of the pleopod cycle frequency using fast Fourier transformation. The ampli-

Table 2. Meganyctiphanes norvegica. Statistical comparison of differences in swimming capacity (maximum and average propulsive force $[\mathrm{N}]$ /wet weight $[\mathrm{kg}]$ ) in krill between cohorts (Age-groups 1 and 2) and seasons (May and September)

\begin{tabular}{|c|c|c|c|c|c|c|c|}
\hline \multirow[t]{2}{*}{ Source } & \multirow[t]{2}{*}{ df } & \multicolumn{3}{|c|}{ Max. propulsive force/wet weight } & \multicolumn{3}{|c|}{ Avg. propulsive force/wet weight } \\
\hline & & SS & $F$-value & p-value & $\mathrm{SS}$ & $F$-value & p-value \\
\hline Cohort & 1 & 60.84 & 23.26 & 0.0001 & 1.492 & 4.000 & 0.0467 \\
\hline Season & 1 & 1.029 & 0.393 & 0.531 & 0.018 & 0.048 & 0.8261 \\
\hline Cohort $\times$ Season & 1 & 32.68 & 12.49 & 0.0005 & 2.596 & 6.959 & 0.0089 \\
\hline Residual & 224 & 585.93 & & & 83.57 & & \\
\hline
\end{tabular}




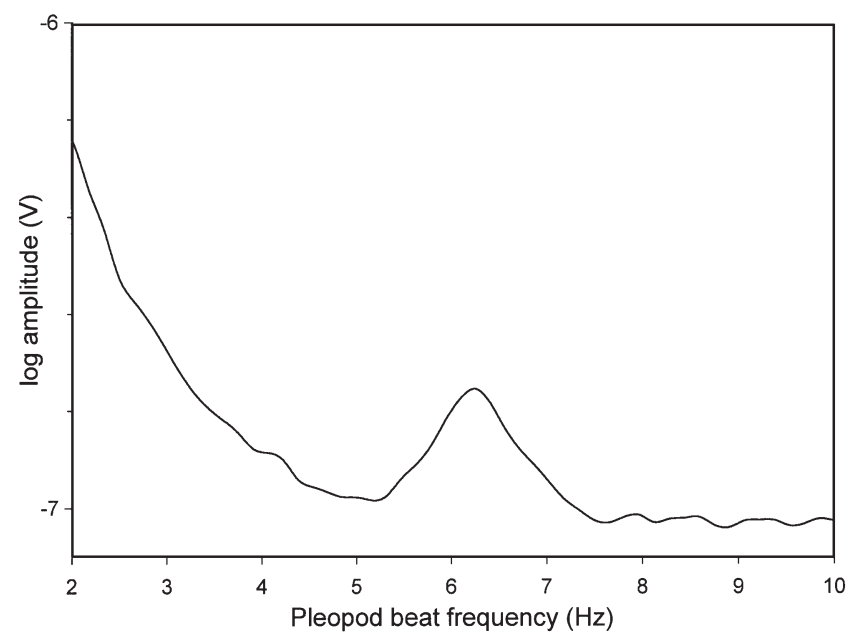

Fig. 6. Meganyctiphanes norvegica. Cycle frequency of pleopod beat using fast Fourier transformation. Trace from May 2001, showing a male, $37 \mathrm{~mm}$, moult Stage $\mathrm{C}$ with a pleopod beat frequency peak at $6.3 \mathrm{~Hz}$

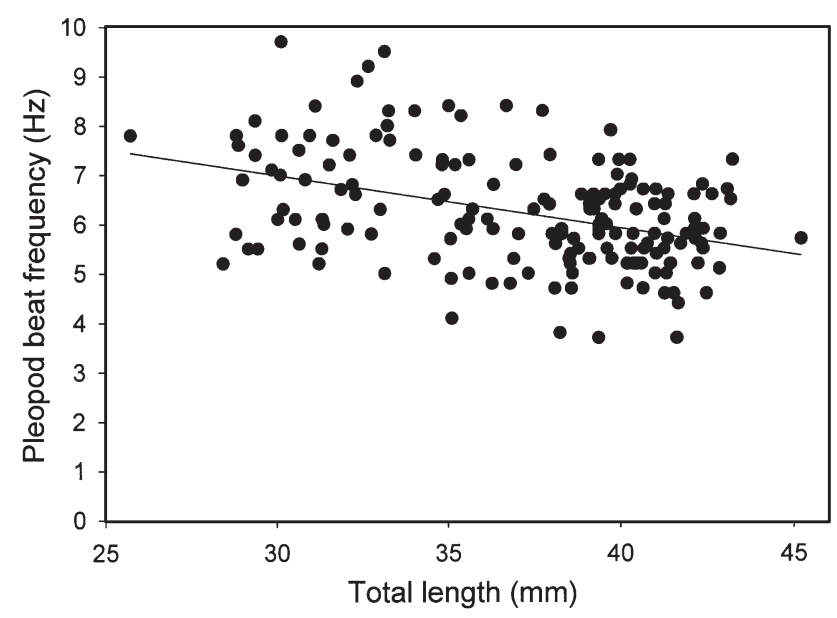

Fig. 7. Meganyctiphanes norvegica. Negative relationship between pleopod beat frequency and size of krill. There is a significant linear relationship between beat frequency and total length (ANOVA, $\mathrm{p}<0.05), \mathrm{n}=167, y=-0.107 x+10.18$,

$$
\mathrm{r}^{2}=0.162
$$

tude spectra is calculated using the natural logarithmic amplitude values (measured in V). Linear regression analysis demonstrated a significant negative relationship between pleopod beat frequency and total length (ANOVA, $\left.F_{1,165}=31.918, \mathrm{p}<0.05\right)$. Larger krill thus have a lower beat frequency than smaller ones (Fig. 7). The high amplitude values in the low frequency part of the spectra $(<4 \mathrm{~Hz})$ is due to the swimming behaviour of krill, i.e. they perform swimming bouts rather than continuous swimming, which are high in energy (much higher than the pleopod beat) but low in frequency.

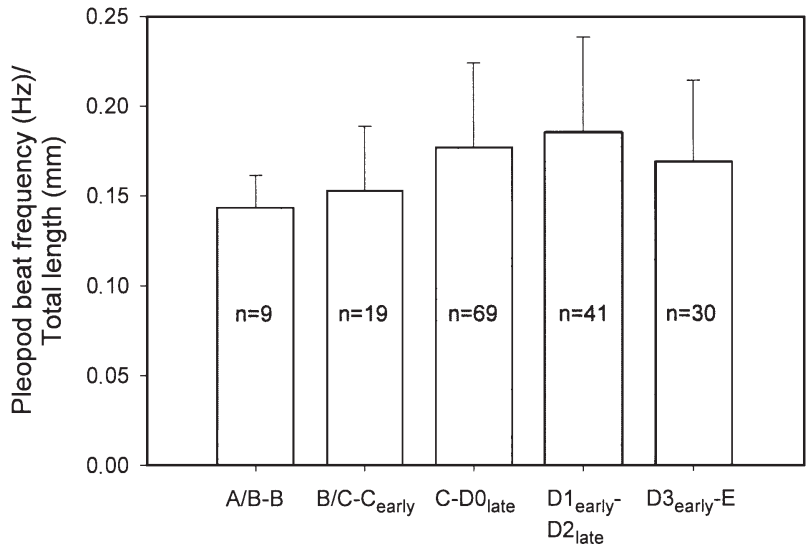

Fig. 8. Meganyctiphanes norvegica. Relationship between pleopod beat frequency normalised to size and moult stage $(+\mathrm{SD})$

\section{Pleopod beat frequency in females vs males}

The pleopod beat frequency in females was significantly higher than in males (ANOVA, $F_{1,166}=15.864$, $\mathrm{p}<0.05)$. Pleopod beat frequency was normalised to size by dividing frequency by length, since the size of the krill was negatively related to the beat frequency. The average total length of the krill used in the pleopod beat experiment was $37.1 \mathrm{~mm}$ (SD 4.29) and a female of this size would then have a pleopod beat frequency of $7.4 \mathrm{~Hz}$ (SD 0.25), and a male $6.1 \mathrm{~Hz}$ (SD 0.17).

\section{Pleopod beat frequency vs moult stage}

The effect of different moult stages on pleopod beat frequency can be seen in Fig. 8. The moult stages were divided into the same 5 groups as mentioned above. There was a significant difference in pleopod beat frequency between moult stages (ANOVA, $F_{4,163}=2.756$, $\mathrm{p}<0.05)$. According to a Student-Newman-Keuls test, Stage A/B-B was significantly different from $\mathrm{D} 1_{\text {early }}-\mathrm{D} 2_{\text {late }}$ indicating that newly moulted krill swam with a lower beat frequency.

\section{DISCUSSION}

A major dilemma in studying the behaviour of micronekton such as krill is that in situ observations are difficult to perform because these animals generally live in a habitat that is difficult to observe and control. Furthermore, the alternative, controlled experiments in the laboratory have the drawback that the animals are exposed to stressful artificial circumstances. How- 
ever, measuring relative swimming capacity in freeswimming crustaceans entails a lot of practical constraints. Krill in the present study were certainly exposed to stress both during capture, handling and during measurements of swim capacity and pleopod beat rate. However, the stress levels with respect to handling, attaching the animal to an arm, and light exposure were minimised as far as practically possible and were similar for all experimental animals. Against these general constraints we argue that the method we have developed gives reproducible results that can be used for comparative purposes. The method does not yield any absolute measures of power output in units of energy per unit time, but gives a measure of individual propulsive force, an individual swimming capacity that certainly is a function of absolute power output. Absolute measures, if available, could possibly be of use for advanced quantitative modelling of energy expenditure of natural krill aggregations performing vertical and horizontal migrations, but only if the stress introduced by putting the animal in the experimental situation could be quantified. Awaiting such developments, we believe that to aid interpretations of demographic phenomena observed in the field, the method proposed here holds merit since it provides a tool for comparisons of the swimming ability of different life stages of krill and other pelagic crustaceans.

Our result - that larger krill have a greater swimming capacity than smaller ones - might be expected, and it is also likely that this is related to swimming speed, as noted in other studies (cf. Kils 1981). The most likely reason is that large krill have larger pleopod and setal area than smaller specimens, resulting in a higher propulsion efficiency. It is worth noting that the pleopod beat frequency is not necessarily related to swimming capacity (and thus swimming speed). The pleopod beat frequency of Meganyctiphanes norvegica (about $6 \mathrm{~Hz}$ ) matches the findings of Wiese \& Ebina (1995). These authors also carried out measurements on Euphausia superba and found a lower beat frequency of 3.5 to $5 \mathrm{~Hz}$ in that species. E. superba is larger, growing up to $60 \mathrm{~mm}$, than $M$. norvegica which has a maximum size of ca. $40 \mathrm{~mm}$. All the results, along with those of Kils (1981), confirm that the pleopod frequency decreases with increasing animal size. To avoid sinking, a $20 \mathrm{~mm}$ long $M$. norvegica needed frequency of 8 to $9 \mathrm{~Hz}$, while at 25 to $35 \mathrm{~mm}$ it was about $5 \mathrm{~Hz}$. E. superba of 40 to $50 \mathrm{~mm}$ length only needed 2.5 to $3 \mathrm{~Hz}$. Frank \& Widder (1994) also noticed a similar relationship between beat frequency and body size in the deep-sea shrimp Oplophorus gracilirostris.

The fact that the frequency of the pleopod beat differs with size of the animal may partly explain why schools of krill often consist of specimens of the same size (Hamner et al. 1983). If krill in a school are sorted by size, synchronized swimming may be facilitated. According to Patria (2001), Meganyctiphanes norvegica can synchronize the beat of the pleopods using flow receptors on the antennulae by registering the frequency of the turbulent flow caused by a conspecific in the school. The adjustment of swimming speed in a school, however, does not only depend on adapting pleopod beat rate among school members, but also on the way the pleopod stroke is executed. Both length (amplitude) and the way the branches of these limbs (especially the endopods and exopods) are positioned are important, as was elegantly demonstrated by Kils (1981).

In conclusion, a small krill, although having a higher pleopod beat rate than a large one, generally swims slower and has less swimming capacity than a large krill. In the context of vertical migration, we speculate it is possible that, during the nocturnal ascent phase, large animals would arrive near to the surface earlier than small ones. The same would apply around dawn, large krill would arrive at depth sooner than small ones during descent.

Our finding that the pleopod beat frequency is higher in females than in males $(7.4 \mathrm{vs} 6.1 \mathrm{~Hz}$ ) is puzzling. We did not find any difference in total mass or volume between sexes. The only morphological difference between males and females concerning the pleopods is the presence of a petasma in males and that might have some influence on their beat performance, but is probably not that crucial. A factor that may affect buoyancy and thus pleopod beat frequency is lipid content, which varies with ovarian development. A mature female with a fully developed ovary can have a total lipid content in the gonad twice as high as males and non-reproductive females of the same size (Cuzin-Roudy et al. 1999). Various stages of ovarian development were undoubtedly present in the material but no estimates of lipid content were made. Females with well developed ovaries have a bulkier thorax but this was not pronounced in our experimental animals. However, a high lipid content ought to decrease the sinking rate, and thus probably reduces rather than increases the need for a high pleopod beat frequency in females during ascent.

Tarling et al. (1999) demonstrated that postmoulted specimens (Stages A and B) did not undertake the diel vertical migration to the same extent as inter- and premoulted ones, but stayed in the deep to a greater extent. Our results support these findings and provide experimental verification that newly moulted krill have a weaker swimming capacity. The reasons for the weaker swimming capability in Stages A and B are most likely that the hormonally controlled moulting in crustaceans (Quackenbush 1986) involves major anatomical and physiological reorganisation. The animal 
produces a new exoskeleton, including setae, muscular attachment, corneas, limbs and gills within the confines of the old one. In the newly moulted animal, the cuticle is very soft with a poor muscular attachment and all tissue in the epidermis is in the process of reorganisation. This puts a substantial physiological strain on the organism, as indicated by Paranjape (1967), who found that the average respiration rate increased by $34.2 \%$ during moulting in Euphausia pacifica. The increased metabolism, together with the fact that krill do not feed during moulting, would support the idea that krill should be more quiescent during this phase in the moult cycle. This is sensible since a low pleopod beat activity leaves more of the available energy reserves for the demanding moult process. Also the soft cuticle of the newly moulted krill may mechanically affect the swimming capacity in a negative fashion. Similar traits are also found in benthic crustaceans. For example, Cromarty et al. (1991) reported that postmoulted Stages A and B of juvenile lobster Homarus americanus showed weaker swimming capability than individuals in the premoult and intermoult stages. These phenomena combine to make the newly moulted krill vulnerable to predation. From an evolutionary perspective, to counteract this potentially dangerous but necessary life-phase (females can only receive spermatophores when newly moulted; CuzinRoudy \& Buchholz 1999) with more quiescent/cryptic behaviour in the form of less swimming activity seems highly adaptive.

The interaction found between season and cohort may show demographic effects in vertical migration. Our results show that in May, there was a greater difference in mean body size between the 2 cohorts present $(9.1 \mathrm{~mm})$ than in September $(5.9 \mathrm{~mm})$. The size factor of swimming capacity is normalised in the analysis, but the size dependent difference in pleopod beat rate remains, which should be more evident in May, since the size difference between cohorts was the largest during this season. Hence, one might expect a higher extent of separation between cohorts during vertical migration, especially in the beginning of the reproductive season when the cohorts differ most in size.

Acknowledgements. The present work was done while 2 of us (M.L.J. and E.G.) enjoyed support of EU TMR-ARI funding to Kristineberg Marine Research Station. Support from the Royal Society and from the Royal Swedish Academy of Sciences is also gratefully acknowledged. The crew of the 'Arne Tiselius' did a great job collecting krill; many thanks to Janine Cuzin-Roudy for excellent supervision in krill moult-staging technique; Hans Olsson was very helpful with technical support; Hans Nilsson helped with statistical issues and Peter Shelton kindly allowed us to borrow some equipment. Valuable comments from 4 anonymous referees helped to improve the paper.

\section{LITERATURE CITED}

Bergström BI (2000) The biology of Pandalus. Adv Mar Biol 38:55-245

Bergström BI, Strömberg JO (1997) Behavioural differences in relation to pycnoclines during vertical migration of the euphausiids Meganyctiphanes norvegica (M. Sars) and Thysanoessa raschii (M. Sars). J Plankton Res 19:255-261

Buchholz F (1982) Drach's molt staging system adapted for euphausiids. Mar Biol 66:301-305

Buchholz F (1991) Moult cycle and growth of Antarctic krill Euphausia superba in the laboratory. Mar Ecol Prog Ser 69:217-229

Buchholz F, Boysen-Ennen E (1988) Meganyctiphanes norvegica (Crustacea: Euphausiacea) in the Kattegat: studies on the horizontal distribution in relation to hydrography and zooplankton. Ophelia 29:71-82

Buchholz F, Buchholz C, Reppin J, Fischer J (1995) Diel vertical migrations of Meganyctiphanes norvegica in the Kattegat: comparison of net catches and measurements with acoustic doppler current profilers. Helgol Meeresunters 49:849-866

Cromarty SI, Cobb JS, Kass-Simon G (1991) Behavioural analysis of the escape response in the juvenile lobster Homarus americanus over the molt cycle. J Exp Biol 158: 565-581

Cuzin-Roudy J (1987) Gonad history of the Antarctic krill Euphausia superba Dana during its breeding season. Polar Biol 7:237-244

Cuzin-Roudy J, Buchholz F (1999) Ovarian development and spawning in relation to the moult cycle in Northern krill, Meganyctiphanes norvegica (Crustacea: Euphausiacea), along a climatic gradient. Mar Biol 133:267-281

Cuzin-Roudy J, Albessard E, Virtue P, Mayzaud P (1999) The scheduling of spawning with the moult cycle in Northern krill (Crustacea: Euphausiacea): a strategy for allocating lipids to reproduction. Invertebr Reprod Dev 36:163-170

Dalpadado P, Ellertsen B, Melle W, Dommasnes A (2000) Food and feeding conditions of Norwegian springspawning herring (Clupea harengus) through its feeding migrations. ICES J Mar Sci 57:843-857

Einarsson H (1945) Euphausiacea I. Northern Atlantic species. Dana-Rep Carlsberg Found 27:1-185

Frank TM, Widder EA (1994) Comparative study of behavioural sensitivity thresholds to near-UV and blue-green light in deep-sea crustaceans. Mar Biol 121:229-235

Gonzalez-Gurriaran E, Freire J, Parapar J, Sampedro MP, Urcera M (1995) Growth at moult and moulting seasonality of the spider crab, Maja squinado (Herbst) (Decapoda: Majidae) in experimental conditions: implication for juvenile life history. J Exp Mar Biol Ecol 189:183-203

Hamner WM, Hamner PP, Strand SW, Gilmer RW (1983) Behavior of Antarctic Krill, Euphausia superba: chemoreception, feeding, schooling, and molting. Science 220: $433-435$

Hardy AC, Bainbridge R (1954) Experimental observations on the vertical migrations of plankton animals. J Mar Biol Assoc UK 33:409-448

Kils U (1981) The swimming behaviour, swimming performance and energy balance of Antarctic krill, Euphausia superba. BIOMASS Sci Ser 3:1-122

Land MF (1992) Locomotion and visual behaviour of midwater crustaceans. J Mar Biol Assoc UK 72:41-60

Liljebladh B, Thomasson MA (2001) Krill behaviour as recorded by acoustic doppler current profilers in the Gullmarsfjord. J Mar Syst 27:301-313

Lipcius RN, Herrnkind WF (1982) Molt cycle alterations in be- 
haviour, feeding and diel rhythms of a decapod crustacean, the Spiny lobster Panulirus argus. Mar Biol 68:241-252

Mauchline J (1980) The biology of mysids and euphausiids. In: Blaxter JHS, Russel FS, Yonge M (eds) Advances in marine biology, Vol 18. Academic Press, London, p 371-623

Mauchline J, Fisher LR (1969) The biology of euphausiids. In: Russel FS, Young M (eds) Advances in marine biology, Vol 7. Academic Press, London, p 1-454

Onsrud MSR, Kaartvedt S (1998) Diel vertical migration of the krill Meganyctiphanes norvegica in relation to physical environment, food and predators. Mar Ecol Prog Ser 171: 209-219

Paranjape MA (1967) Molting and respiration of euphausiids. J Fish Res Board Can 24:1229-1240

Passano LM (1960) Molting and its control. In: Waterman TH (ed) The physiology of crustacea, Vol 1. Academic Press, New York, p 473-536

Patria MP (2001) Comparative measurement of antennular sensitivity towards signals of turbulent water flow including the flow field generated by conspecifics in Nordic krill, Meganyctiphanes norvegica (M. Sars, 1857), (Euphausi-

Editorial responsibility: Otto Kinne (Editor),

Oldendorf/Luhe, Germany acea). Berichte aus der Biologie, University of Hamburg, Shaker Verlag, Aachen, p 1-81

Quackenbush LS (1986) Crustacean endocrinology, a review. Can J Fish Aquat Sci 43:2271-2282

Roe HSJ, James PT, Thurston MH (1984) The diel migrations and distributions within a mesopelagic community in the Northeast Atlantic 6. Medusae ctenophores amphipods and euphausiids. Prog Oceanogr 13:425-460

Siegel V, Nicol S (2000) Population parameters. In: Everson I (ed) Krill: biology, ecology and fisheries. Fish and aquatic resources, Series 6. Blackwell Scientific Publications, Oxford, p 103-149

Tarling GA, Cuzin-Roudy J, Buchholz F (1999) Vertical migration behaviour in the northern krill Meganyctiphanes norvegica is influenced by moult and reproductive processes. Mar Ecol Prog Ser 190:253-262

Torgersen T (2001) Visual predation by the euphausiid Meganyctiphanes norvegica. Mar Ecol Prog Ser 209:295-299

Wiese K, Ebina Y (1995) The propulsion jet of Euphausia superba (Antarctic krill) as a potential communication signal among conspecifics. J Mar Biol Assoc UK 75:43-54

Submitted: May 10, 2002; Accepted: December 3, 2002

Proofs received from author(s): March 10, 2003 